\title{
Políticas de apoio aos idosos em situação de dependência: Europa e Brasil
}

\author{
Support policies for dependent older adults: Europe and Brazil
}

Maria Cecília de Souza Minayo (https://orcid.org/0000-0001-6187-9301) ${ }^{1}$

Jurilza Maria Barros Mendonça (https://orcid.org/0000-0001-5827-6286) ${ }^{2}$

Girliani Silva de Sousa (https://orcid.org/0000-0002-0988-5744) ${ }^{3}$

Telma Freitas da Silva Pereira (https://orcid.org/0000-0002-4185-4542) ${ }^{1}$

Raimunda Matilde do Nascimento Mangas (https://orcid.org/0000-0002-7284-7740) ${ }^{1}$

${ }^{1}$ Departamento de Estudos sobre Violência e Saúde Jorge Careli, Escola Nacional de Saúde Pública Sergio Arouca, Fiocruz. Av. Brasil 4036/700, Manguinhos. 21040-361 Rio de Janeiro RJ Brasil.

maminayo@terra.com.br

${ }^{2}$ Núcleo de Estudos e Pesquisas em Política Social, Centro de Estudos Avançados Multidisciplinares, Universidade de Brasília. Brasília DF Brasil. ${ }^{3}$ Departamento de Enfermagem Clínica e Cirúrgica, Escola Paulista de Enfermagem, Universidade Federal de São Paulo. São Paulo SP Brasil.

\begin{abstract}
This theoretical essay discusses longterm care policies for dependent older adults. It aims to analyze the content and strategies that guided the formulation of the so-called "dependence policies" in some European states, seeking guidance to formulate actions related to the same issue in the Brazilian case. The knowledge bases are official documents and scientific papers analyzing the institutionalized proposals. The study shows that all the countries investigated included dependence policies within their social security system framework. Some offer total protection, while others only partial protection to older adults and family caregivers. However, older adults and their caregivers never fail to receive the care they need. In Brazil, some local experiences meet comprehensive care requirements. Initiatives of Belo Horizonte and São Paulo are narrated, and while important, they are not policies. They are successful cases that can evolve to increase social awareness or simply disappear as non-institutionalized experiences. The issue addressed in this paper is very relevant, due to the inexorable fact of the accelerated growth of the long-lived population, which requires care from others the most.

Key words Dependent older adults, Public policy, Health services, Long term care
\end{abstract}

Resumo Neste ensaio teórico discutem-se políticas sobre cuidados de longa duração para pessoas idosas dependentes. O objetivo é analisar o conteúdo e as estratégias que guiaram a formulação das chamadas "políticas de dependência" em alguns estados europeus, buscando orientações para a realização de ações relativas à mesma questão no caso brasileiro. As bases de conhecimento são documentos oficiais e artigos científicos que descrevem $e$ analisam a institucionalização das propostas. $O$ estudo mostra que os países europeus aqui analisados incluíram as politicas sobre a dependência nos marcos de seu sistema de seguridade social; alguns oferecem proteção total, outros, apenas parcial ao idoso e ao cuidador familiar. Em nenhum deles, a pessoa idosa dependente deixa de receber os cuidados de que precisa. No Brasil, há algumas experiências locais que atendem aos requisitos de atenção integral. São narradas uma de Belo Horizonte e outra de São Paulo. Embora sejam importantes, tais iniciativas não constituem uma política, são casos exitosos que podem evoluir para o aumento da consciência social ou se esvaírem como experiências não institucionalizadas. A questão tratada neste artigo é de grande relevância, pelo fato inexorável do crescimento acelerado da população longeva, a que mais depende do cuidado de terceiros. Palavras-chave Idoso dependente, Políticas públicas, Serviços de saúde, Cuidado de longa duração 


\section{Introdução}

Este artigo trata dos mecanismos públicos de proteção à pessoa dependente. Seu objetivo é compreender o conteúdo e as estratégias que guiaram a formulação das chamadas "políticas de dependência" na União Europeia, com destaque para alguns países, na busca de possíveis orientações para o debate e a formulação de ações relativas à mesma questão no caso brasileiro.

Tal objetivo se justifica porque, segundo especialistas que estudam as consequências do aumento da longevidade nas sociedades contemporâneas, a questão crucial hoje é, de um lado, promover o envelhecimento ativo; de outro, cobrir as necessidades de cuidados e atenção a pessoas dependentes, cujo número se incrementa pelo aumento acelerado da população em idade avançada ${ }^{1}$. A questão é social e econômica, pois a transformação das estruturas demográfica e familiar leva a um aumento da proporção de idosos relativamente à de jovens e, consequentemente, a um envelhecimento das sociedades, $o$ que pressupõe novas fontes de despesas para os sistemas de proteção social ${ }^{2}$.

O mundo se despertou tardiamente para a questão do envelhecimento. A Organização das Nações Unidas (ONU) colocou esse tema na sua agenda apenas a partir de 1956, embora the tenha dado pouca atenção. Somente em 1982 a ONU promoveu a "I Assembleia Mundial sobre

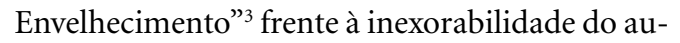
mento do número de idosos nos países europeus. Nesse evento, ocorrido em Viena, foi definido o marco de 60 anos para se considerar uma pessoa como idosa nos países em desenvolvimento e de 65 anos, nos países desenvolvidos. Também foi apresentado um plano de ação para prover segurança econômica, social e de integração desse grupo etário no processo de desenvolvimento dos países. Em 2002, em Madrid ocorreu a "II Assembleia Mundial sobre o Envelhecimento"4. Nela foi revisto o Plano de Ação de Viena de 1982, pois se constatou que o ritmo de crescimento acelerado da população idosa incluía também os países em desenvolvimento. Dessa reunião saíram três recomendações prioritárias: engajamento dos idosos no desenvolvimento social; promoção de sua saúde e bem-estar e garantia de ambiente propício e favorável para envelhecer.

Nos diferentes documentos da ONU e da Organização Mundial de Saúde ${ }^{5}$, a noção de velhice como vulnerabilidade foi dando lugar à visão dos idosos como um grupo social ativo e importante para as sociedades. Essa visão positiva continua e é expressamente adotada por autores como Gaymu et al. ${ }^{6}$ que preveem uma população longeva cada vez mais saudável. Mas, igualmente, há uma preocupação com os idosos dependentes, o que remonta ao século XIX, e de forma sistemática e institucionalizada, na Europa pós-Segunda Guerra Mundial, quando se formularam políticas específicas, em geral, propondo ações conjuntas do setor de saúde e do setor de assistência social, dentro dos marcos do sistema de seguridade social?.

Atualmente, a Organização Panamericana de Saúde $(\mathrm{OPAS})^{8}$ conclamou os países da Região das Américas a que fortaleçam seus sistemas de saúde e de proteção social para responderem às demandas de cuidados de longa duração que, em quantidade, triplicarão nas próximas três décadas, passando de oito milhões a 27 ou a $30 \mathrm{mi}-$ lhões até 2050. No mesmo sentido, a Organização dos Estados Americanos, em 15 de junho de 2015, já havia aprovado a Convenção Interamericana sobre a Proteção dos Direitos Humanos da Pessoa Idosa, por meio de um documento juridicamente vinculante. Um item especifico dispõe que os "Estados Partes devem adotar medidas para desenvolver um sistema integral de cuidados que leve em conta a perspectiva de gênero e o respeito à dignidade e integridade física e mental do idoso, para garantir-lhe o gozo efetivo de seus direitos humanos por meio de cuidados de longo prazo". O Brasil foi um dos primeiros países a assinar a Convenção. No entanto até o presente momento não a ratificou, vez que sua ratificação implica na obrigação de adotar medidas para implementá-la. Desde 07 de março de 2018, a proposta de ratificação está parada na Câmara Federal para ser levada a plenário.

Cumprindo os objetivos propostos deste artigo são tratados os seguintes tópicos: (1) em que bases filosóficas e normativas, a proteção social e os cuidados com a pessoa dependente têm sido pensados e regulados na Europa; (2) como o cuidado vem sendo praticado numa amostra de países europeus; e (3) qual é a situação do Brasil.

\section{Método}

Metodologicamente este ensaio teórico que utiliza material secundário consiste numa análise descritiva sobre dois temas: (1) os sistemas de bem-estar social europeus tendo em vista que a política de cuidado com a pessoa idosa dependente faz parte de sua institucionalidade; (2) a situação do Brasil quanto a leis, normas, dificul- 
dades e possibilidades de ação frente à situação dos idosos dependentes. A pesquisa para elaboração do artigo foi realizada entre janeiro e maio de 2020 .

Os temas são tratados dentro de uma lógica que vai do geral para o particular: (1) mudanças da sociedade contemporânea e respostas sociais da Europa ${ }^{10,11}$; (2) surgimento e bases do Welfare State ${ }^{12-15} ;$ (3) conceito de envelhecimento e dependência segundo a Organização Mundial de Saúde ${ }^{5,16,17}$; (4) normativas do Conselho e da Comissão Europeia sobre família, envelhecimento e dependência ${ }^{18-20}$; (5) posição da Organização dos Estados Americanos ${ }^{9}$ sobre a situação das pessoas com dependência na Região; (6) políticas sociais oficiais relativas à seguridade, envelhecimento direitos e serviços do Brasil ${ }^{21-28}$. Outros textos utilizados apoiam a descrição de alguns sistemas dos países selecionados e ajudam a entender o rumo da institucionalização de cada um. Por fim, além de artigos sobre a situação do envelhecimento e da dependência no Brasil, narram-se duas experiências locais de cuidados.

A escolha dos países com políticas específicas de proteção dos idosos dependentes obedeceu ao objetivo estratégico - quase didático - de conhecer para inspirar a ação possível na mesma direção no Brasil. Foram selecionadas referências sobre a experiência da Dinamarca, um dos países de referência em proteção social; da Alemanha, cujas origens do sistema de proteção inspiraram a Europa, desde o século XIX; da França e da Espanha, por serem culturas mais próximas ao Brasil. A apropriação dos documentos foi realizada com foco nos objetivos e na finalidade do artigo.

\section{Estado de bem-estar e políticas de cuidados com a pessoa dependente}

O chamado Estado de Bem-Estar Social, tal como conhecido hoje, tem raízes no século XIX, mas é uma invenção da Europa no pós-Segunda Guerra Mundial, com o intuito de intervir nos processos de produção e distribuição da riqueza, visando a proteger os indivíduos e atender a suas necessidades fundamentais. A proposta, embora aplicada de forma diferente em cada país, ressalta que o cuidado oferecido a qualquer cidadão não deve depender da benevolência de ninguém, pois emerge da solidariedade e da interdependência entre as pessoas ${ }^{10,11,29}$. Portanto, a política econômica e a política social são pensadas de forma coordenada, reforçando-se mutuamente, garantindo, ao mesmo tempo, a geração de riqueza e os direitos dos cidadãos. Algumas características distinguem o Welfare State Europeu: sua singularidade entre os modelos de seguridade de outros países; suas quatro liberdades ${ }^{14}$ : da pessoa, dos bens, do capital e do cidadão social. É a ideia de um estado social que tem permitido a tradição da democracia, da solidariedade, dos direitos civis e sociais. A concepção de cidadania subjacente a esse arranjo contrasta com o liberalismo sem limites e com a noção de cuidar por caridade ${ }^{30}$, pois dela se depreende que proteger a população é garantir a dignidade humana.

A forma como o arcabouço filosófico e normativo comum se organiza é peculiar a cada Estado que compõe a União Europeia e, dentre as tipologias com que são denominados, são clássicas as criadas por Titmuss ${ }^{12}$ e aperfeiçoadas por Esping-Andersen ${ }^{13}$. Esses autores consideram: um modelo liberal ou anglo-saxão, que inclui Irlanda e Reino Unido; um conservador-corporativo ou continental, que engloba Alemanha, Áustria, Bélgica, França, Luxemburgo e Países Baixos; e um socialdemocrata ou escandinavo, que reúne Dinamarca, Finlândia e Suécia. A essa categorização, alguns autores somaram o chamado "modelo mediterrâneo”, composto por Espanha, Grécia, Itália e Portugal, com características diferentes dos três e tardio, tendo se desenvolvido após a queda dos regimes ditatoriais que os marcaram, a partir de $1970^{15,31,32}$.

O modelo anglo-saxão caracteriza-se pelo papel residual do Estado, que se restringe a assegurar o atendimento das necessidades fundamentais de grupos sociais específicos, notadamente dos que não são capazes de sobreviver por seus próprios meios. Os cuidados com os demais contam com sistemas de seguros e incentivos do próprio Estado, sobretudo, por meio de isenções fiscais. No regime continental, o Estado assume papel mais importante que o mercado e menos importante que a família. $\mathrm{O}$ acesso aos benefícios depende do pagamento de contribuições, o principal mecanismo de financiamento. O modelo se caracteriza por elevado grau de regulamentação do mercado de trabalho, visando a assegurar o emprego estável e a atender às necessidades da família por meio de salário e benefícios. No entanto, ninguém, mesmo fora dos mecanismos do mercado de trabalho, fica sem amparo. O modelo escandinavo caracteriza-se pelo papel central do Estado relativamente ao mercado e à família. $\mathrm{O}$ acesso aos benefícios independe do pagamento de contribuições, pois são financiados por impostos. $\mathrm{O}$ regime se caracteriza por elevada taxa de emprego, sobretudo de mulheres, de forma que possam conciliar a vida familiar e profissio- 
nal. No modelo mediterrâneo, o Estado possui um papel mais importante que o mercado e menos relevante que a família. Os laços de solidariedade se ampliam à família estendida. Os benefícios variam em função da ocupação e do pagamento de contribuições. Para os que estão em risco, os cuidados independem do pagamento de contribuições. São financiados por impostos ${ }^{30,33,34}$.

A referida tipologia ajuda a entender a realidade, mas não a constitui, pois ela se modifica e se adapta aos contextos históricos. Por exemplo, atualmente, a União Europeia, mantendo suas políticas de proteção enfrenta problemas que lhe exigem criatividade redobrada, tendo em vista que a população idosa praticamente dobrará, passando de 85 milhões em 2008 para 151 milhões em 2060. Há a previsão de que o número de pessoas com idade igual ou superior a 80 anos triplicará, passando de 22 milhões em 2008 para 61 milhões em $2060^{35}$. O aumento da longevidade cada vez mais pressiona os sistemas de seguridade social. De acordo com Fargues ${ }^{36}$, esse movimento demográfico coloca em xeque o tamanho, a riqueza e o contrato social, pois a população mundial continuará aumentando e a europeia se estabilizará ou encolherá. O contingente de trabalhadores diminuirá, num movimento combinado com o aumento inédito da população idosa. Apesar de refletir uma tendência universal, o envelhecimento da população é duas vezes mais acentuado na Europa se comparado com o resto do mundo ${ }^{36}$.

$\mathrm{O}$ continente europeu há muito vem se ocupando com o aumento dos idosos dependentes. Documento seminal foi o do Comitê de Ministros do Conselho da Europa, com recomendações para todos os países membros da União Europeia (EU), exortando sobre a necessidade de proteger as pessoas dependentes e estabelecendo alguns parâmetros gerais de ação ${ }^{18}$. A dependência foi definida como a necessidade de ajuda ou assistência para execução das atividades da vida cotidiana, ou como um estado em que se encontram as pessoas, por razões ligadas à falta ou perda de autonomia física, psíquica ou intelectual. E que por isso essas pessoas têm necessidade de assistência e ajuda na vida diária, e, de modo particular, para realizar cuidados pessoais. Nessa recomendação, vários elementos práticos foram estabelecidos e serviram de orientação para os Países. São muitos os estudos sobre o tema feitos por Comissões Europeias ${ }^{19}$, dentre os quais, ressalta-se o elaborado por Spasova et al. ${ }^{37}$, um estudo da The European social policy network denominado Challenges in long-term care in Europe, a study of national policies.
Nesse texto avaliativo ${ }^{37}$, a Comissão ressalta que a provisão de Cuidados de Longa Duração (LTC) na Europa é caracterizada por diferenças significativas entre e dentro dos países membros. Principalmente: na forma como é organizada (se por provedores públicos, com fins lucrativos ou por entidades não-governamentais); prestada (por atendimento domiciliar ou atendimento institucional); financiada (em dinheiro, benefícios em espécie ou pagamentos diretos); e na maneira como os recursos são gerados (por tributação geral, previdência social obrigatória ou seguro privado voluntário). E conclui que parte substancial dos LTC são exercidos por cuidadores familiares informais. Porém, a extensão em que esse cuidado é complementado por cuidados formais e públicos varia muito e constitui uma economia oculta: o setor de serviços pessoais e domésticos possui um dos níveis mais altos de trabalho não declarado.

\section{Exemplos de políticas e ações \\ a favor de idosos dependentes}

Como já dito, os casos aqui apresentados obedecem a uma lógica descritiva e analítica com caráter estratégico. Os países citados se enquadram nas classificações de Titmuss ${ }^{12}$, Esping Andersen ${ }^{13}$ e Rhodes et al. ${ }^{15}$.

Dinamarca - O setor público dinamarquês tem um histórico importante na proteção aos idosos. Os que requerem cuidados podem escolher entre provedores públicos, privados, parente, vizinho, amigo ou conhecido como responsáveis por assisti-los. A política de bem-estar social é financiada por impostos. A responsabilidade administrativa pelo cuidado é do município que oferece atendimento residencial ou de asilo por meio de assistência profissional. Os cuidados em casa são prestados sob a forma de ajuda pessoal e apoio nas tarefas domésticas. Ser cuidador familiar é uma opção, ninguém é forçado, mas a pessoa que o presta tem um contrato de trabalho que lhe garante pagamento, mediante algumas condições como um salário por hora. A prestação de cuidado deve ser superior a $20 \mathrm{~h}$ semanais ${ }^{38}$. Se julgar necessário, o município pode exigir que o cuidador participe de cursos ou treinamentos. Se ele ficar doente ou sair de férias, cabe ao município encontrar um substituto. É incomum se encontrarem familiares cuidando de idosos, o que é mais usual em minorias étnicas. Ressalta-se que o comprometimento com a proteção social e o bem-estar da pessoa idosa dependente são definidos como investimento e não como gasto, pois 
promovem estabilidade econômica e diminuem riscos de agravos e internações hospitalares ${ }^{38}$.

Alemanha - A Social Law XI 1, a German long term care insurance de janeiro de 1995 faz parte da seguridade social e trata da provisão financeira para os que necessitam de cuidados. Essa lei introduziu na sociedade o chamado $5^{\circ}$ pilar da seguridade social, ao lado do direito à saúde, do seguro contra acidentes, das pensões e do seguro desemprego. Esse $5^{\circ}$ pilar financia cuidados para os idosos que precisam, com base em contribuições que fizeram em seus empregos remunerados e por meio de aportes de seguros privados. $\mathrm{O}$ objetivo primordial da lei é possibilitar que os idosos possam ser cuidados por seus familiares em domicílio. Para usufruir dos direitos previstos em lei, os idosos precisam provar que possuem necessidades físicas por doença ou incapacidade. $\mathrm{O}$ grau de necessidade determina o pagamento pela quantidade de horas de atendimento por sema$\mathrm{na}^{38}$. Os benefícios que a população dependente recebe recobrem três estágios de acordo com o grau de perda de autonomia. Para cada caso é feito um relatório pelo serviço médico do seguro de saúde para estabelecer o valor do benefício. Para se tornar cuidador familiar na Alemanha, o parente de um idoso frágil precisa se qualificar e realizar um teste sobre seu próprio estado de saúde. Os valores pagos à família por prestar assistência são legalmente fixados e dependem do nível de atendimento. Críticos consideram que esses contratos são muito precários: o nível de remuneração está claramente abaixo do nível de salário padrão na Alemanha e a pessoa que cuida não tem garantias trabalhistas. Embora consiga quatro semanas de afastamento caso adoeça ou tire férias, ela não recebe pagamento nesse tempo de folga ${ }^{38}$.

França - Desde 1990 existem políticas públicas voltadas para a proteção social da pessoa idosa que requer cuidados de longa duração. $\mathrm{O}$ "Cheque Emprego Serviço Universal" permite que as famílias busquem auxiliares para cuidar dos idosos ou para realizar serviços de limpeza doméstica nas suas residências. A “Alocação Personalizada de Autonomia" (Allocation Personnalisée d'Autonomie) foi criada em 2002 e beneficia qualquer pessoa dependente com 60 anos ou mais. $\mathrm{O}$ valor depende do grau de dependência, da renda do beneficiário e do fato de o idoso residir em domicílio ou em instituição ${ }^{39}$. Atualmente, existe um projeto em tramitação no senado francês a favor da assistência às pessoas idosas dependentes. Uma premissa dessa proposta é investir em cuidados no domicílio e reduzir gastos com instituições de longa permanência (ILPI) (hoje, 85\% dos idosos dependentes na França estão em ILPI). O pressuposto é que ofertar recursos financeiros e de suporte assistencial aos idosos em casa tem impacto positivo na garantia de bem-estar, longevidade, qualidade de vida e traz efeitos significativos no tratamento de doenças crônicas, prevenção de agravos e promoção da saúde ${ }^{40}$. Esse projeto de lei é bem amplo e focaliza os seguintes pontos: (1) criar um programa de rastreamento de fragilidade, de acordo com as recomendações do "Atendimento Integrado a Pessoas Idosas", desenvolvido pela Organização Mundial da Saúde ${ }^{17}$, segundo níveis de dependência e de incapacidade funcional; (2) subsidiar a adaptação dos domicílios para evitar quedas; (3) criar um aplicativo visando à autoavaliação das necessidades e oferta de orientações individualizadas. Tais medidas deverão ser financiadas pelo imposto de $0,3 \%$, sobre as aposentadorias, instituído em 2013.

Espanha - O modelo de proteção social baseado na ajuda mútua local e familiar marca os países mediterrâneos. É o caso da Espanha, onde o tema da dependência, que sempre esteve a cargo da família, foi se modificando aos poucos ${ }^{41} \mathrm{e}$ se tornou assunto de Estado. A Ley de Promoción de Autonomia y Atención a las Personas em Situación de Dependencia aprovada em $2006^{42}$, coroa um grande movimento de cidadãos, pesquisadores e profissionais de serviços sociais e de saúde. A referida lei reconhece os cuidados prestados às pessoas que vão perdendo sua autonomia como um direito subjetivo. Seus princípios mais significativos são: universalidade do acesso aos cuidados; colaboração entre serviços sociais e serviços sanitários; e participação da iniciativa privada e do terceiro setor na prestação dos serviços. A lei determina: (1) engajamento de todos os níveis de administração pública (governo central, autonomias e municípios); regulamentação do catálogo de serviços, segundo grau de dependência; (3) critérios de qualidade e a eficiência na prestação dos serviços; (4) qualificação dos profissionais; e (5) normas e sanções às infrações contra os direitos das pessoas dependentes ${ }^{43}$.

Os serviços aos idosos dependentes são prestados primordialmente nos municípios, têm caráter prioritário e englobam: prevenção e promoção da autonomia; teleassistência domiciliar; ajuda para afazeres domésticos; centros de dia e de noite; atenção institucionalizada e prestações econômicas vinculadas ao serviço de cuidado familiar; ajuda técnica e adaptação domiciliar. Há ainda uma prestação econômica que pode 
ser acionada e depende do grau de dependência e da capacidade financeira do beneficiário. Sua finalidade é permitir que as pessoas dependentes possam contratar um cuidador durante um determinado número de horas para auxiliá-las nas atividades básicas de vida diária ${ }^{7}$. O cuidador familiar também pode receber um auxílio econômico e lhe são garantidos programas de informação, formação e períodos de descanso. A responsabilidade institucional pelo cumprimento da lei é do "Ministério de Salud, Consumo y Servicios Sociales", por meio do "Instituto de Mayores y Servicios Sociales da Secretaria de Estado y Servicios Sociales" ${ }^{\prime 3}$.

\section{O que o Brasil tem feito pela pessoa idosa dependente: leis, normativas e ações}

O Estado brasileiro tem leis e normativas importantes de proteção à pessoa idosa. A Política Nacional do Idoso ${ }^{23}$, o Estatuto do Idoso ${ }^{25}$ e a Política Nacional de Saúde da Pessoa Idosa ${ }^{25}$ envolvem todas as esferas administrativas e governamentais para garantia dos direitos da população acima de 60 anos. Sobre os mais vulneráveis, mesmo antes da Política de Saúde ${ }^{26}$ ter sido implantada, vinham sendo construídas Redes Estaduais de Assistência à Saúde do Idoso ${ }^{24}$. Oficialmente, a Política de Saúde ${ }^{25}$ propõe que todas as instâncias do SUS estejam atentas à população idosa vulnerável, definida como: o idoso que vive em ILPI; encontra-se acamado; esteve hospitalizado recentemente por qualquer razão; apresenta doenças causadoras de incapacidade funcional por acidente vascular encefálico; síndromes demenciais e outras doenças neurodegenerativas; etilismo; neoplasia terminal; amputação de membros; apresente incapacidade funcional para executar atividades básicas da vida diária (AVD); vive em situação de violência doméstica; e tem 75 anos ou mais de idade.

No âmbito da Assistência Social, o Conselho Nacional da área aprovou a Resolução no 109 , de 11 de novembro de $2009^{27}$, que define e tipifica os serviços socioassistenciais, organizados por níveis de complexidade: proteção social básica e proteção social especial de média e alta complexidade. Nessa última modalidade se incluem as pessoas idosas e as portadoras de deficiência para as quais se preveem proteção em abrigo, casa-lar, casa de passagem, residência inclusiva ou serviço de acolhimento em república.

O Ministério da Previdência e Assistência Social, por meio da Portaria $\mathrm{n}^{\circ} 73^{22}$, desde 10 de maio de 2001 já estabelecia normas de funciona- mento de serviços à pessoa idosa, definindo as modalidades de atendimento, respeitando complexidades e especificidades. Para as mais vulneráveis, as modalidades preceituadas são: centro de convivência, centro-dia, casa-lar, assistência domiciliar e atendimento integral institucional. Ponto importante do ponto de vista da proteção social, $84,3 \%$ das pessoas idosas recebem aposentadoria, pensão, ou o benefício de prestação continuada (BPC) ${ }^{44}$. E recentemente, o Superior Tribunal de Justiça fixou a tese de que, comprovada a necessidade de assistência permanente de terceiro, é devido o acréscimo de $25 \%$ a todas as modalidades de aposentadoria conforme previsto no artigo 45 da lei $8.213 / 1991^{21}$.

Apesar dos aparatos legais e normativos das áreas da Previdência, Saúde e Assistência Social, a grande maioria dos que sofrem com a perda de autonomia vive sob o amparo apenas de suas famílias ${ }^{45}$. Na Reforma da Previdência que acabou de ser aprovada ${ }^{28}$, não há nenhuma proposta de proteção para as pessoas que, em diferentes graus, perdem sua autonomia física, mental, econômica e social, apesar do crescimento acelerado da população acima de 80 anos, a mais vulnerável à dependência.

Camarano et al. ${ }^{46}$ mencionam que pelo menos três tipos de ação precisariam ser asseguradas aos idosos brasileiros dependentes e a seus familiares: centros-dia; instituições de longa permanência (ILPI); e apoio no âmbito familiar. Os centros-dia, em geral, são insuficientes nas respostas: a quantidade de Centros de Assistência Social é pequena frente às necessidades; muitos idosos dependentes em níveis iniciais que poderiam usufruir desse apoio têm dificuldades de acesso aos locais; e são escassas as atividades multidisciplinares que previnem a perda de autonomia. Num país continental como o Brasil há apenas 3.548 instituições de longa permanência (ILPI), das quais somente 6,6\% são públicas e mais de $60 \%$ são filantrópicas e subfinanciadas. Nelas vivem 83.870 pessoas com mais de 60 anos, o que representa menos de $1 \%$ da população idosa brasileira ${ }^{47}$. Ora, se menos de $1 \%$ dos idosos está em residência de longa permanência, a quase totalidade dos que se encontram em estado de dependência, $-34,5 \%$ do total da população idosa, segundo a Pesquisa Nacional de Saúde (PNS) realizada em conjunto pelo Instituto Brasileiro de Geografia e Estatística (IBGE) e o Ministério da Saúde (MS), e analisada por Lima-Costa et al..$^{48,49} \mathrm{e}$ Malta et al. ${ }^{50}$ - estão a cargo das famílias. Essa reflexão leva à conclusão sobre a omissão do Estado em relação aos idosos mais vulneráveis. Note-se que existe consenso entre os 
estudiosos de que as pessoas com incapacidades funcionais e problemas sociais, dentre os velhos, são as que mais sofrem e são vítimas de violência, negligências e abandonos ${ }^{1,44,51-53}$.

Existem algumas boas práticas multidisciplinares e com foco no cuidado com a pessoa dependente. No entanto, elas constituem experiências localizadas ainda que muito importantes, por seu potencial de universalização por meio de uma política pública. Mencionam-se aqui dois casos que articulam atenção especializada e atenção primária, dos quais, um situado em Belo Horizonte e outro em São Paulo.

Uma das iniciativas acontece na cidade de Belo Horizonte e se chama "Programa Maior Cuidado”. Esse programa que começou em 2011 constitui uma parceria entre o Centro de Referência de Assistência Social (CRAS) e a Estratégia Saúde da Família. Por meio dessa colaboração, idosos dependentes e suas famílias são selecionados para contar com um cuidador formal em alguns dias e horários, de acordo com o grau de necessidade aferido tecnicamente. É construído um plano de cuidados junto com a pessoa idosa e sua família para os participantes do programa. A colaboração da Assistência Social e da Estratégia Saúde da Família garante ações adequadas com foco no bem-estar e na minimização de agravos. Atualmente, o programa acompanha cerca de 500 idosos/mês e atende prioritariamente os que se encontram em extrema pobreza. Avaliações mostram que diminuiu a demanda desse grupo por hospitalizações e por internações em ILPI. O recurso financeiro que mantém o programa vem da arrecadação fiscal do município ${ }^{54}$.

Outra iniciativa é o "Programa Acompanhante de Idosos" (PAI), promovido pela Secretaria Municipal da Saúde de São Paulo desde 2002. Ele inclui avaliação e monitoramento do caso específico; elaboração de um plano de cuidado; e educação permanente dos acompanhantes. Atualmente conta com 22 equipes conjuntas da área da saúde e da assistência social, com formação especializada em geriatria. A proposta é resultado de uma parceria entre a Associação Saúde da Família, o Centro Social Nossa Senhora do Bom Parto e a Superintendência de Atenção à Saúde do Serviço Social da Construção Civil e visa ao cuidado biopsicossocial em domicílio, para pessoas idosas em situação de fragilidade clínica e social. É-lhes oferecido apoio e suporte para as atividades da vida diárias e para suprir outras necessidades de saúde e sociais ${ }^{55}$.

Em resumo, comparando a situação do Brasil com a de países da União Europeia em relação ao idoso dependente, pode-se concluir que aqui faltam propósito e foco. No caso europeu, houve e há um investimento da União Europeia e de cada país membro na promoção de uma política de Estado sobre o cuidado, as responsabilidades, a definição das práticas e a indicação das fontes de receitas para atendimento às pessoas dependentes, na maioria, idosas ${ }^{7}$. O fundamento filosófico de tais posturas e decisões, como lembra Jones ${ }^{14}$, é a ideia que valoriza o "cidadão social" numa "uma sociedade para todas as idades". Da forma como a questão está sendo tratada no Brasil, torna-se quase impossível uma ação efetiva que contemple as reais necessidades da pessoa dependente e de sua família, como se conclui a seguir.

As iniciativas das três áreas governamentais responsáveis pelas políticas relativas à pessoa idosa, em muitos casos, se sobrepõem. Em segundo lugar, em maioria, elas não saem do papel ou não alcançam as demandas do idoso em sua realidade concreta. Nos serviços sociais, grande parte das propostas não tem financiamento adscrito e depende de articulação intersetorial. Nos serviços de saúde, o idoso é invisível em sua especificidade, cabendo-lhe e a seus cuidadores competirem por atendimento. $\mathrm{O}$ máximo que as famílias de baixa renda hoje conseguem - com ressalva para alguns programas localizados - é a assistência pontual da Estratégia Saúde da família, dos Núcleos de Apoio à Saúde da Família e dos Centros de Assistência Social. Aos pobres cabe contar com a solidariedade da comunidade, de organizações não governamentais e de entidades religiosas que conseguem algumas doações, por exemplo, de fraldas e de cadeiras de roda. A adaptação do domicílio é precária, assim como o são as condições de moradia. Faltam orientações e treinamento para as famílias, em particular para a pessoa que cuida. Há poucos centros-dia ou vagas em instituições de longa permanência (ILPI). Ponto muito importante constatado numa pesquisa recente sobre idosos dependentes e suas famílias ${ }^{56}$, não se observam mobilizações desses atores sociais em defesa de seus direitos, sendo eles os maiores interessados em obter apoio social e do Estado.

\section{Considerações finais}

Este artigo apenas exemplifica o que hoje a União Europeia e o Brasil estão fazendo pelos idosos dependentes. Por que se focaliza a Europa? Porque é nessa região do mundo onde o Estado de Bem -Estar Social funciona, ainda que com todas as falhas que os críticos apontam. A Política de Bem 
-Estar Social da Europa vem garantindo direitos à população envelhecida e assistência qualificada às pessoas dependentes, por meio do rastreio das fragilidades e vulnerabilidades, o que geralmente tem ocorrido por um trabalho conjunto entre o setor saúde e o de assistência social que atuam com cuidadores formais, informais e apoio técnico.

O caso brasileiro merece considerações pela generosidade das leis e ausência de medidas efetivas para cumpri-las. O problema central é que falta foco na questão da dependência. Os casos positivos de atuação, aqui citados, são muito importantes porque sinalizam caminhos de possibilidades. No entanto, esses exemplos não constituem uma política. Urge trabalhar para que a proteção às pessoas idosas dependentes entre na pauta do governo brasileiro e não seja apenas uma questão de responsabilidade das famílias.

A lição que os países bem sucedidos no apoio adequado aos idosos dependentes ensinam é que uma boa política a favor desse grupo social conjuga diretrizes: equilíbrio entre responsabilidades públicas, privadas, sociais e familiares; entendimento de que manter os idosos nos próprios lares é preferível à institucionalização; mas para que o cuidado oferecido em casa seja adequado, é preciso investir nos cuidadores familiares, oferecendo-lhes apoio no campo do conhecimento, das práticas e financeiramente.

Concluindo, assinala-se que este artigo possui várias limitações. Não houve uma busca exaustiva de documentos oficiais e nem de autores que analisem e que critiquem as políticas de dependência na Europa. Também, a bibliografia brasileira sobre idosos dependentes não foi integralmente consultada. Contudo, o aporte dos documentos oficiais e as referências analíticas permitem ao leitor fazer seu próprio juízo sobre a urgência de uma política específica para a população idosa dependente do cuidado de terceiros no Brasil, objetivo último desta reflexão.

\section{Colaboradores}

MCS Minayo coordenou e foi a principal responsável pela elaboração de trabalho. JMB Mendonça e GS Sousa contribuíram para a elaboração teórico-metodológica e pela análise. RMN Mangas e TFS Pereira contribuíram com a revisão bibliográfica e com a leitura final do material. 


\section{Referências}

1. Baltes PB, Smith J. Novas Fronteiras para o futuro do envelhecimento: a velhice bem-sucedida do idoso jovem aos dilemas da Quarta Idade. A Terceira Idade 2006; 7(36):7-31.

2. Taylos-Gooby P. Open Markets versus Welfare Citizenship: Conflicting Approaches to Policy Convergence in Europe. Social Policy Administration 2003; 37(6):539-554.

3. United Nations (UN). Report of the World Assembly on Aging. Viena: UN; 1982. [cited 2020 Apr 25]. Available from: https://www.un.org/esa/socdev/ageing/documents/Resources/VIPEE-English.pdf

4. United Nations (UN). Second world Assembly on Aging. Madrid: UN; 2002. [cited 2020 Apr 25]. Available from: https://www.un.org/development/desa/ ageing/madrid-plan-of-action-and-its-implementation/second-world-assembly-on-ageing-2002.html

5. World Health Organization (WHO). International Classification of Impairments, Disabilities and Handicaps: A Manual of Classification relating to the consequences of disease. Genebra: WHO; 1980.

6. Gaymu J, Ekamper O, Beets G. Who will be caring for Europe's dependent elders in 2030? Sociologie and Culture 2007; 62(4):675-706.

7. Rodriguez P. El apoyo informal en la provisión de cuidados a las personas con dependencias. Madrid: Forum de Políticas Feministas; 2004.

8. Organização Pan-Americana de Saúde (OPAS). Plano de ação sobre a Saúde dos Idosos, incluindo o envelhecimento ativo e saudável: Relatório Final. Washington: OPAS; 2019.

9. Organização dos Estados Americanos (OEA). Convenção Interamericana sobre a Proteção dos Direitos Humanos dos Idosos. Washington: OEA; 2015. (AG/ doc.5493/15 corr.1).

10. Offe C. Política sociale, solidarietà e stato nazionale. Torino: Fondazione Giovanni Agnelli; 1993.

11. Offe C. Capitalismo desorganizado. São Paulo: Ed. Brasiliense; 1995.

12. Titmuss R. Essays on the welfare state. London: Allen \& UnWin; 1976

13. Esping-Andersen G. The Three Worlds of Welfare Capitalism. Princeton: Princeton University Press; 1990.

14. Jones C. The new perspectives on the welfare State in Europe. London, New York: Routledge; 1996.

15. Rhodes M, Ferrera M, Hemerijck A. The future of social Europe: recasting work and welfare in the new economy. Oxford: Oxford University Press; 2000.

16. World Health Organization (WHO). A life course perspective of maintaining independence in older age. Genève: WHO; 1999. [cited 2020 Apr 7]. Available from: http://whqlibdoc.who.int/hq/1999/WHO_ HSC_AHE_99.2_life.pdf?ua=1

17. World Health Organization (WHO). World report on ageing and health. Genebra: WHO; 2015 [cited Apr 7]. Available from: https:/www.who.int/ageing/publications/world-report-2015/es/

18. European Commission. Recomendation 1.035. Aging population in Europe: economic and social consequences. Brussels: European Union; 1998

19. European Commission. Ageing Report: Economic and Budgetary Projections for the 28 EU Member States (2013-2060). Brussels: European Commission; 2015.
20. European Communities (EC). Communication Toward an Europe for all ages. Promoting prosperity and solidarity. Brussels: EC; 1999.

21. Brasil. Lei n.8.213, de 24 de julho de 1991. Dispõe sobre planos de Benefícios da Previdência Social e dá outras providências. Diário Oficial da União 1991; 25 jul.

22. Brasil. Ministério da Previdência e Assistência Social (MPAS). Portaria no 73, de 10 de maio de 2001. Normas de funcionamento de serviços à pessoa idosa. $\mathrm{Di}$ ário Oficial da União 2001; 11 maio.

23. Brasil. Lei n. 8.842, de 04 de janeiro de 1994. Dispõe sobre a Política Nacional do Idoso, cria o Conselho Nacional do Idoso e dá outras providências. Diário Oficial da União 1994; 5 jan.

24. Brasil. Ministério da Saúde (MS). Redes Estaduais de Atenção à Saúde do Idoso: guia operacional e portarias relacionadas. Brasília: MS; 2002.

25. Brasil. Lei n. 10.741, de $1^{\circ}$ de outubro de 2003. Dispõe sobre o Estatuto do Idoso e dá outras providências. Diário Oficial da União 2003; 3 out.

26. Brasil. Ministério de Saúde. Portaria no 2.528, de 19 de outubro de 2006. Aprova a Política Nacional de Saúde da Pessoa Idosa. Diário Oficial da União 2006; 20 out.

27. Brasil. Conselho Nacional de Assistência Social. Resolução no 109; de 11 de novembro de 2009. Define e tipifica os serviços socioassistenciais, organizados por níveis de complexidade. Diário Oficial da União 2009; 12 nov.

28. Brasil, Emenda Constitucional no 103 , de 12 de novembro de 2019. Reforma da Previdência Social. Diário Oficial da União 2019; 13 nov.

29. Baldwin P. The politics of social solidarity: class bases of the European welfare state, 1875-1975. Cambridge: Cambridge University Press; 1990.

30. Wolf PJW, Oliveira GC. Os Estados de Bem-Estar Social da Europa Ocidental: tipologias, evidências e vulnerabilidades. Economia e Sociedade 2016; 25(3):661694.

31. Guillén A, Petmesidou M. The private-publicmix in Southern Europe. What changed in the last decade. In: Kaiser S, editor. Welfare state transformations. London: Macmillan; 2008. p. 56-78.

32. Moreno-Fuentes FJ, Matute EP. Desafíos del estado de Bienestar en Noruega y España. Nuevas políticas para atender a los nuevos riesgos sociales. Madrid: Tecnos; 2015.

33. Paquy L. Les systèmes européens de protection sociale: Une mise en perspective: Paris: Mire; 2004.

34. Isakjee A. Welfare State regimes: a literature review. Birmingham: IRIS working paper series; 2017.

35. Sanja I. The rights of older Adults in the European Union. Dados 2013; 56(1):185-205.

36. Fargues P. International Migration and Europe's Demographic Challenge. Fiesole: Robert Schuman Centre for Advanced Studies, European University Institute; 2011.

37. Spasova S, Baeten R, Coster S, Ghailani D, Peña-Casas $\mathrm{R}$, Vanhercke B. Challenges in long-term care in Europe, a study of national policies. Brussels: European Commission; 2018 
38. Frericks P, Jensen PH, Pfau-Effinger B. Social rights and employment rights related to family care: Family care regimes in Europe. J Aging Stud 2014; 29:66-77.

39. Devetter FX, Jany-Catrice F, Ribault T. Les services à la personne. Paris: La Découverte; 2009.

40. Buzin A. Viellir en bonne santé. Stratégie de prévention de la perte d'autonomie, Solidarités-Santé. Paris: Gouvernement français; 2020.

41. Ezquerra S, Salanova MP, Pla M, Subirats EJ, editores. Edades en transición. Envejecer en el siglo. XXI. Barcelona: Editorial Planeta; 2016.

42. España. Ministerio de Salud y Asuntos Sociales. Libro Blanco de Atención a las personas en situación de dependencia. Aprobado en 2006. [cited 2020 Abr 20]. https://www.imserso.es/InterPresent2/groups/imserso/ documents/binario/libroblanco.pdf

43. Castedo RA. Políticas sociales y prestación de servicios a las personas dependientes y a sus familias. Granada: Universidad de Granada; 2006.

44. Batista AS, Jaccoud LB, Aquino L, El-Mor PD. Envelhecimento e dependência: desafios para organização da proteção social. Brasília: MPS; 2008.

45. Andrade LM, Sena ELDS, Pinheiro GML, Meira EC, Lira LSSP. Políticas públicas para pessoas idosas no Brasil: uma revisão integrativa. Cien Saude Colet 2013; 18(12):3543-3552.

46. Camarano AA, Kanso S, Mello, JL, Carvalho, DF. Cuidados de Longa Duração para a População Idosa no Brasil. Rio de Janeiro: IPEA; 2018.

47. Camarano AA, Kanso S. As instituições de longa permanência para idosos no Brasil. Rev. Bras. Estud. Popul. 2010; 27(1):232-235.

48. Lima-Costa MF, Manbrini JVM, Peixoto SV, Malta DC, Macinko J. Socioeconomic inequalities in activities of daily living limitations and in the provision of informal and formal care for non institutionalized older Brazilians: National Health Survey, 2013. Int J Equity Health 2016; 15(1):137-145.2s.

49. Lima-Costa MF, Peixoto SV, Malta, DM, Szwarcwald CL, Mambrini JVM. Cuidado informal e remunerado aos idosos no Brasil. Rev Saude Publica 2017; 51(Supl. $1): 6 s$
50. Malta DC, Bernal RTI, Lima MG, Araújo SSCD, Silva MMAD, Freitas MIDF, Barros MBDA. Doenças crônicas não transmissíveis e utilização de serviços de saúde: análise da Pesquisa Nacional de Saúde no Brasil. Rev Saude Publica 2017; 51(Supl.1):4s.

51. Minayo MCS. O imperativo de cuidar da pessoa dependente. Cien Saude Colet 2019; 24(1):247-252.

52. Buckinx F, Rolland Y, Reginster, JY, Ricour C, Petermans J, Bruyyère O. Burden of frailty in the elderly population: perspectives for a public health challenge. Arch Public Health 2015; 73(1):19-25.

53. Mendonça JMB. Idosos no Brasil: políticas e cuidados. Brasília: Editora Juruá; 2016.

54. Belo Horizonte. Programa Maior Cuidado. Belo Horizonte: Prefeitura; 2011. [cited 2020 Abr 20]. Available from: https://prefeitura.pbh.gov.br/smasac/programa -maior-cuidado.

55. São Paulo. Programa de Acompanhante de Idoso. São Paulo: Prefeitura; 2006. [cited 2020 Abr 20]. Available from: https://www.prefeitura.sp.gov.br/cidade/secretarias/saude/atencao_basica/pessoa_idosa/index. php?p=5498\#pai

56. Minayo MCS. Estudo situacional dos idosos dependentes que residem com suas famílias visando a subsidiar uma política de atenção e de apoio aos cuidadores. Rio de Janeiro: Fiocruz; 2019. (Relatório de Pesquisa).

Artigo apresentado em 04/05/2020

Aprovado em 11/08/2020

Versão final apresentada em 13/08/2020

Editores chefes: Maria Cecília de Souza Minayo, Romeu Gomes, Antônio Augusto Moura da Silva. Editora Associada da área de Saúde do Idoso: Joselia Oliveira Araújo Firmo 